\title{
Genetic Divergence Studies in Tomato (Solanum lycopersicum L.)
}

\author{
Mahantesh Jogi*, H.B. Lingaiah, K.M. Indiresh, T.H. Singh, \\ D.K. Samuel and R.K. Ramachandra
}

Department of Vegetable Science, College of Horticulture Bengaluru, Karnataka - 560065, India

*Corresponding author

\section{Keywords \\ Tomato, Genetic divergence, Clusters and genotypes}

\section{Article Info}

\section{Accepted:}

16 August 2018

Available Online:

10 September 2018

A B S T R A C T

As the information, on the nature and magnitude of variability for yield and other characters present in germplasm pool owing to genetic and non-genetic causes, is an important basic pre-requisite for starting any systematic breeding programme to identify superior lines or varieties. Thus, this investigation was undertaken involving 200 genotypes of tomato (Solanum lycopersicum L.) with following objective as genetic divergence studies in tomato. Genetic diversity among 200 tomato genotypes was worked out using $\mathrm{D}^{2}$ statistics. On the basis of genetic distance, these genotypes were grouped in to 8 clusters. Cluster-I topped in having maximum of 177 genotypes followed by cluster-II having 17 genotypes while remaining clusters cluster III, IV and V, VI, VII, VIII included one genotype each. Clustering was mainly due to either geographical locations or due to genotype. The maximum intra-cluster distance was observed in Cluster-II (2965.87) followed by Clusters-I (2384.00) which were identified genetically divergent. The maximum inter-cluster distance was noticed between Cluster-VII and Cluster-VIII showed maximum inter cluster distance (37547.80) followed by that between cluster-V and cluster-VIII (25781.20). Among 13 characters included for $\mathrm{D}^{2}$ analysis, Number of fruits per plant contributed maximum to divergence followed by plant height and have a major role in improvement of fruit yield in tomato. Therefore, crossing between genotypes belonging to Cluster- I and II as well as between Cluster- VII and III are expected to give maximum heterosis.

\section{Introduction}

Tomato (Solanum lycopersicum L.) belonging to the family solanaceae was once considered poisonous and inedible, has now become one of the most popular and extensively consumed vegetable. It stands unique among vegetables because of its high nutritive values and uses. Tomato is consumed either fresh, cooked or processed into various products like juice, ketchup, sauce, puree, whole canned fruit and is one of the main ingredient of 'pizzas'. Tomatoes are important source of Vitamin A, Vitamin $\mathrm{C}$ and minerals.

Tomato cultivation has become increasingly popular since the mid-nineteenth century because of its varied climatic tolerance and high nutritive value. In India it occupies an area of about 0.80 million hectares with the 
production of 19.67 million tons and average productivity of 24.4 t/ha (Anon., 2017a). In Karnataka it occupies an area of 0.63 lakh hectares with a production of 21.38 lakh tons with an average productivity of $33.55 \mathrm{t} / \mathrm{ha}$ (Anon., 2017b).

The magnitude of divergence between two groups under consideration is provided by $\mathrm{D}^{2}$ statistic developed by Mahalanobis (1936). It considers the variation produced by any character and their consequent effect that it bears on other characters. The technique in the form of generalized distance was first used by Mahalanobis (1936), in an anthropometric survey of the united province in India. For the first time $D^{2}$ statistic was applied for biological population by Nair and Mukharji (1960) to classify the natural and plantation teak tree types. Its application was extended later to taxonomic studies.

Murthy and Pavate (1962) observed that $\mathrm{D}^{2}$ analysis can be extended to the situations where overlapping species need to be discriminated and also when the discrimination at subspecies level is needed. This technique was subsequently used in different vegetable crops.

The choice of parents for hybridization depends on genetic diversity of parents. Precise information on the nature and degree of genetic divergence would help the plant breeder in choosing the selective parents for hybridization. The expression of heterosis is influenced by genetic diversity of parents. Several reports are available to show that hybrids between genetically diverse parents manifest greater heterosis than those between more closely related parents (Ram and Panwar, 1970; Moll and Stuber, 1974).

The importance of variability, character association, path analysis and divergence has been well recognized by plant breeders. In tomato, most of the studies made so far in this aspect are based on single environment only. Since, the inter-relationships are known to vary from season to season from different characters, it is essential to study under different environmental conditions. Keeping in view the above facts present investigation was undertaken with an objective to study of genetic diversity in two hundred genotypes of tomato based on thirteen important traits, to help in selecting promising and genetically diverse parents for desired improvement.

\section{Materials and Methods}

Two hundred genetically diverse tomato accessions comprising of established varieties and advanced breeding lines were grown inaugmented block design (ABD) during kharif, 2015-2016 at Department of Vegetable Science, College of Horticulture Bengaluru, Karnataka. The experimental field is located at an altitude of $930 \mathrm{~m}$ above MSL, $12^{\circ} 581$ North latitude and $77^{\circ} 351$ East-longitude in the Eastern Dry Zone (Zone-5) of Karnataka.

The parental seeds of genotypes were sown in protrays of 98 cells in the nursery and four week old seedlings were transplanted in main field. All the package of practices recommended by UHS, Bagalkot were followed. Data relating to thirteen qualitative and quantitative traits viz., plant height $(\mathrm{cm})$, number of primary branches per plant, days to first flowering, days to 50 percent flowering, fruit width $(\mathrm{cm})$, fruit length $(\mathrm{cm})$, number of fruits per plant, average fruit weight $(\mathrm{g})$, number of locules per fruit, pericarp thickness $(\mathrm{mm})$, yield per plant $(\mathrm{kg})$, total soluble solids ( ${ }^{\circ}$ Brix), firmness $\left(\mathrm{kg} / \mathrm{cm}^{2}\right)$.

Mahalonobis (1936) $\mathrm{D}^{2}$ statics was used for assessing the genetic divergence between populations comprising 200 tomato genotypes. The original correlated unstandardized character mean values were transformed into 
standardized uncorrelated values to sinythify the componential procedure. The $\mathrm{D}^{2}$ values were obtained as the sum of square of difference between two pairs of corresponding uncorrected value (1/s) of any two genotypes (Rao, 1952).

A total of $n(n-1) / 2 D^{2}$ values were calculated. Using all values, the genotypes were grouped into clusters using Tocher's method as described by Rao, (1952). Intra and intercluster distances were calculated by adopting the formula given by Singh and Choudhary (1979).

\section{Results and Discussion}

The analysis of variance revealed that the presence of significant variability among tomato genotypes for all characters studied. Based on the relative magnitude of $\mathrm{D}^{2}$ estimates, 200 genotypes of tomato were grouped into 8 clusters (Table 1). It is conformed the statement of Singh et al., (2008), (Khapte and Jansirani, 2014) and (Lekshmi and Celine 2016) the genotypes grouped together are less divergent than the ones, which are placed in different clusters.
Among them cluster-I topped in having maximum of 177 genotypes followed by cluster-II having 17 genotypes while remaining cluster-III, IV, V, VI, VII and VIII included one genotype each. The selection and choice of parent mainly depends upon contribution of characters towards divergence. In the present study (Table 2) the relative contribution of different quantitative characters towards expression of genetic divergence was calculated.

The characters like number of fruits per plant $(54.76 \%)$ contributed maximum towards expression of genetic divergence followed by plant height $(25.62 \%)$, average fruit weight (18.26\%), days to first flowering $(0.73 \%)$, days to 50 percent flowering $(0.61 \%)$, number of locules per fruit $(0.02 \%)$, number of branches per plant $(2.04 \%)$, fruit width $(0.01 \%)$ and fruit length $(0.01 \%)$. The divergence of the genotypes was studied on the range of means for each character (Table $3)$. The cluster-VII could be categorized in to high total yield per plant bearing group and the remaining group into medium bearing group. The cluster-VII was having high yield per plant.

Table.2 Relative per cent contribution of different characters to the total divergence in tomato

\begin{tabular}{|c|l|c|}
\hline S. No. & \multicolumn{1}{|c|}{ Character } & Per cent contribution \\
\hline 1 & Plant height $(\mathrm{cm})$ & $25.62 \%$ \\
\hline 2 & Number of branches/plant & $0.01 \%$ \\
\hline 3 & Days to first flowering & $0.73 \%$ \\
\hline 4 & Days to 50 per cent flowering & $0.61 \%$ \\
\hline 5 & Fruit width $(\mathrm{cm})$ & $0.01 \%$ \\
\hline 6 & Fruit length $(\mathrm{cm})$ & $0.01 \%$ \\
\hline 7 & Number of locules per fruit & $0.02 \%$ \\
\hline 8 & Pericarp thickness $(\mathrm{mm})$ & 0.00 \\
\hline 9 & Number of fruits per plant & $54.76 \%$ \\
\hline 10 & Average fruit weight $(\mathrm{g})$ & $18.26 \%$ \\
\hline 11 & Yield per plant $(\mathrm{kg})$ & 0.00 \\
\hline 12 & TSS $\left({ }^{0} \mathrm{~B}\right)$ & 0.00 \\
\hline 13 & Firmness $\left(\mathrm{kg} / \mathrm{cm}^{2}\right)$ & 0.00 \\
\hline
\end{tabular}


Table.1 Clustering pattern of 200 genotypes of tomato based on $\mathrm{D}^{2}$ values

\begin{tabular}{|c|c|c|}
\hline Cluster number & $\begin{array}{l}\text { Number of } \\
\text { genotypes }\end{array}$ & Genotypes included \\
\hline I & 177 & $\begin{array}{l}\text { ARTD-1, ARTD-2, ARTD-3, ARTD-4, ARTD-5, ARTD-6, ARTD-7, ARTD-8, } \\
\text { AOTD-9, AOTD-10, AOTD-11, AOTD-12, AOTD-13, AOTD-14, AOTD-15, AOTD- } \\
\text { 16, AOTD-17, AOTD-18, AOTD-19, AOTD-20, EC-321426, EC-326146, EC- } \\
\text { 338714, EC-338725, EC-338735, EC-339057, EC-357839, EC-362940, Punjab } \\
\text { Varkha Bahar-1, PNR-1, S-12, Punjab Varkha Bahar-2, HisarLal, Punjab Upama, } \\
\text { Punjab Chhuhar, Punjab Kesari, Punjab Ratta, 52135, Azad-T-1, KashiSharad, } \\
\text { KashiAmrith, KashiAnupama, Kalyanpur Type, A Abha, A Saurabh, DT-10, H-24, } \\
\text { PTR-4, PTR-6, Bhagyashree, Dhanashree, Pule Raja, UtkalKumari, Utkal Raja, } \\
\text { Pragnya, Roma, Best of all, PKM, Akshaya, Rajamundri, Guntur Local, A Alok, A } \\
\text { Vikash, A Meghali, A Ahuthi, Madanapalli, PusaSheetal, PusaSadabahar, PusaRohini, } \\
\text { PusaGourava, P-120, Pusa Ruby, S-22, Navodaya, Selection, C-10-2, C-11-2, C-20-1, } \\
\text { CO-3, 41, DVRT-2, EC-13904, C-1-4,C-4-1, EC-501574, EC-501580, EC-501583, } \\
\text { EC-538404, EC-538405, EC-620383, EC-620398, EC-620401, EC-620446, EC- } \\
\text { 620464, EC-620469, EC-620470, Monte Fevarate, Rio Grande, Angoorlata, Ageta-2, } \\
\text { 85, 4, 80, 200, 1P2, 2P2, 4P1, 5T5P6, 6T6P8, 7, 8P3, 10P6, 11P4, 12P1, 15P4, 16P2, } \\
\text { 17P5, 18P3, 19P8, 20, 21, 23P4, 29P4, 30P2, 34P2, 35P2, 36, 37P2, 38P2, 40P4, 43, } \\
\text { 44P2, 45, 46P5, 47P2, 51, 53, 54P3, 55P2, 56P2, 58, 59, 61P4, 62P4, 63P3, 64, 65P5, } \\
\text { 66P1,70, 71P2, 72P2, 74P5, 75P3, 76P1, 77P1, 78P4, 83P1, 84P1, 86P2, 67, 68, } \\
\text { Nandhi, AR-28, Anaga, IIHR-2195, AR-21, AR-4, IHR-2199, IIHR-2198, IHR-2197, } \\
\text { AR-29, IIHR-2196, Utkal Local-2, IIHR-2200, IIHR-2201, H-24-1, Solan-2 }\end{array}$ \\
\hline II & 17 & $\begin{array}{l}\text { EC-338717, EC-357845, UtkalDeepti, CLN-2026, EC-381263, 8,3P2, 9P4, 14P6, } \\
\text { 25P2, 27P2, 28P2, 33P2, 48P4, 73P2, AR-56, Pant-3 }\end{array}$ \\
\hline III & 1 & KashiHemanth \\
\hline IV & 1 & Pant Polyhouse-2 \\
\hline V & 1 & Sioux \\
\hline VI & 1 & Pant Polyhouse \\
\hline VII & 1 & $\mathrm{H}-86$ \\
\hline VIII & 1 & 13P3 \\
\hline
\end{tabular}


Table.3 The mean values of 13 characters for 8 clusters formed by 200 genotypes in tomato

\begin{tabular}{|c|c|c|c|c|c|c|c|c|}
\hline Clusters & I & II & III & IV & $\mathbf{V}$ & VI & VII & VIII \\
\hline Plant height (cm) & 71.95 & 85.49 & 102.33 & 107.33 & 108.33 & 138.33 & 62.00 & 202.33 \\
\hline Number of branches/plant & 6.21 & 7.69 & 7.67 & 6.33 & 6.33 & 6.67 & 6.00 & 6.00 \\
\hline Days to first flowering & 25.11 & 25.65 & 24.00 & 24.00 & 37.00 & 30.00 & 29.00 & 31.00 \\
\hline Days to 50 per cent flowering & 31.29 & 31.53 & 32.00 & 27.00 & 44.00 & 44.00 & 32.00 & 36.00 \\
\hline Fruit width (cm) & 4.45 & 3.79 & 6.35 & 4.70 & 4.85 & 4.65 & 8.15 & 2.55 \\
\hline Fruit length (cm) & 4.24 & 3.74 & 6.70 & 4.75 & 4.15 & 3.50 & 5.85 & 3.40 \\
\hline Number of locules per fruit & 3.79 & 3.29 & 4.00 & 2.00 & 4.00 & 4.00 & 5.00 & 3.00 \\
\hline Pericarp thickness (mm) & 2.98 & 2.93 & 3.49 & 1.62 & 2.60 & 2.90 & 1.49 & 2.60 \\
\hline Number of fruits per plant & 61.16 & 141.63 & 33.51 & 17.29 & 24.68 & 21.05 & 48.85 & 129.52 \\
\hline Average fruit weight (g) & 48.94 & 30.15 & 102.36 & 83.04 & 102.22 & 73.38 & 131.94 & 25.76 \\
\hline Yield per plant (kg) & 2.85 & 4.11 & 3.43 & 1.44 & 2.52 & 1.55 & 6.45 & 3.34 \\
\hline TSS $\left({ }^{0} B\right)$ & 4.20 & 4.73 & 4.93 & 3.67 & 4.00 & 4.00 & 2.93 & 4.00 \\
\hline Firmness $\left(\mathrm{kg} / \mathrm{cm}^{2}\right)$ & 1.35 & 1.28 & 0.49 & 0.78 & 1.00 & 2.33 & 1.13 & 0.95 \\
\hline
\end{tabular}

Table.4 Average intra- and inter-cluster $\mathrm{D}^{2}$ values among 8 clusters for 13 characters formed by 200 genotypes of tomato

\begin{tabular}{|c|c|c|c|c|c|c|c|c|}
\hline Clusters & I & II & III & IV & V & VI & VII & VIII \\
\hline I & 2384.00 & 9597.43 & 5741.52 & 5551.82 & 6981.55 & 7986.40 & 8374.74 & 23456.75 \\
\hline II & & 2965.87 & 18603.19 & 20168.48 & 21079.44 & 20780.29 & 20968.19 & 15267.62 \\
\hline III & & & 0.00 & 707.80 & 440.28 & 2493.36 & 2787.08 & 25181.48 \\
\hline $\mathbf{I V}$ & & & & 0.00 & 888.15 & 1403.30 & 5540.06 & 25043.83 \\
\hline $\mathbf{V}$ & & & & & 0.00 & 1797.30 & 3854.66 & 25781.20 \\
\hline VI & & & & & & 0.00 & 10221.19 & 18205.47 \\
\hline VII & & & & & & & 0.00 & 37547.80 \\
\hline VIII & & & & & & & & 0.00 \\
\hline
\end{tabular}

Bold diagonal values indicates the intra cluster distance 
Among quality parameters the cluster-III and VI had shown high TSS and firmness of the fruit. This indicated that genotypes coming under the Cluster-VII, III and VI may be utilized in breeding programme to get higher yield per plant with high fruit quality in terms of TSS and firmness of the fruits.

Intra clusterD ${ }^{2}$ values (Table 4) ranged from 0.00 to 2965.87. Among the 8 clusters, cluster-II showed maximum intra-cluster diversity $\left(D^{2}=2965.87\right)$ followed by cluster I$\left(D^{2}=2384.00\right)$. Solitary genotype containing clusters III, IV, V and VI, VII and VIII $\left(D^{2}=0.00\right)$ showed zero intra-cluster distance. The genotypes grouped in cluster-VIII were more divergent than the cluster- I, II, III, IV, V, VI and VII the tendency of genotypes from diverse geographic regions group together in one cluster might be due to similarity in requirements and selection under domestic utilization.

Based on distance between clusters i.e. intercluster distance, the maximum divergence was observed between cluster-VII and clusterVIII showed maximum inter cluster distance (37547.80) followed by that between Cluster$\mathrm{V}$ and cluster-VIII (25781.20), Cluster-III and VIII (25181.48), Cluster-IV and VIII (25043.83), Cluster-I and VIII (23456.75), Cluster-II and V (21079.44), Cluster-II and VIII (20968.19), Cluster-II and VI (20780.29), Cluster-II and IV (20168.48), Cluster-II and III (18603.19), Cluster-VI and VIII (18205.47), Cluster-II and VIII (15267.62), Cluster-VI and VII (10221.19), Cluster-I and II (9597.43), Cluster-I and VII (8374.74), Cluster-I and VI (7986.40), Cluster-I and V (6981.55), Cluster-I and III (5741.52), Cluster-I and IV (5551.82), Cluster-IV and VII (5540.06), Cluster-V and VII (3854.66), Cluster-III and VII (2787.08), Cluster-III and VI (2493.36), Cluster-V and VI (1797.30), Cluster-IV and VI (1403.30), Cluster-IV and V (888.15), Cluster-III and IV
(707.80). The inter cluster distance was least between Cluster-III and V (440.28).

Based on quantitative data, the potentiality of the tomato accessions with respect to yield and its attributing characters and the genetically divergent genotypes identified in the present study have wider applicability in planning the future breeding programmes for increasing productivity of tomato. For recovering improved progenies for total yield, crosses can be attempted between the genotypes belonging to the genotypes, Kashi Hemanth, Panth Polyhouse-2, Sioux, Panth Polyhouse, H-86 and 13P3 which were clustered separately in the dendrogram may be utilized as source of parent material in future breeding programme. Hence, genotypes, Kashi Hemanth, Panth Polyhouse2, Sioux, Panth Polyhouse, H-86 and 13P3 may be selected for crossing with other parents for more effective crossing program and to achieve desired segregants for fruit related traits with yield parameters.

\section{Acknowledgements}

I am thankful to, PAU, Ludhiana, IIVR, Varanasi, IIPR, Kanpur, Bureau of Plant Genetic Resources Regional Station (NBPGR) Hyderabad for providing the germplasm for conducting the research.

\section{References}

Anonymous, 2017a, www.nhb. gov. in. National Horticulture Board, Statistical data.

Anonymous, 2017b, Crop wise area and production of horticultural crops in Karnataka. http://www.horticulture.kar.nic.in.

Khapte, P. S. and Jansirani. P., 2014, Genetic diversity studies in tomato (Solanum lycopersicum L.) Genotypes, Trends. Bio. sci., 71(5):1958-1961. 
Lekshmi, S. L. and Celine, V. A., 2016, Genetic diversity studies in tomato (Solanum lycopersicum L.) under protected conditions. Int. J. Curr. Microbiol. App. Sci., 5(4): 212-217.

Mahalanobis, P. C., 1936. On the generalized distance in statistics. Proc. National Acad. Sci. (India), 2: 49-55.

Moll, R. H. and Stuber, C. W., 1974, Quantitative genetics empirical results relevant to plant breeding. Adv. Agron., 26: 277-313.

Murthy, G. S. and Pavate, M. V., 1962, Studies on quantitative inheritance in (Nicotiana tabacum L.) varietal classification and selection by multivariate analysis. Indian J. Genet. Plant. Breed., 22: 68.

Nair, K. R. and Mukherjee, H. K. 1960, Classification of natural and plantation teak (Tectona grandis) grown an different location of India and Burma with respect to its mechanical and physiological properties. Sankhya. 28:120.

Ram, J. and Panwar, D. V. S. 1970, Intraspecific divergence in rice. Indian $\mathrm{J}$. Genet., 30: 1-10.

Rao, C. R., 1952, Advanced Statistical Methods in Biometrical Research. John Willey and Sons, New York, pp. 357359.

Singh, A. K., Sharma, J. P., Kumar, S. and Chopra, S., 2008, Genetic divergence in tomato (Lycopersicon esculentum Mill.). J. Res. SKUAST-J., 7(1):105110.

Singh, R. K. and Chaudhary, B. D., 1979, Biometrical Methods in Quantitative Genetic Analysis. Kalyani Publishers, New Delhi.

\section{How to cite this article:}

Mahantesh Jogi, H.B. Lingaiah, K.M. Indiresh, T.H. Singh, D.K. Samuel and Ramachandra, R.K. 2018. Genetic Divergence Studies in Tomato (Solanum lycopersicum L.). Int.J.Curr.Microbiol.App.Sci. 7(09): 2231-2237. doi: https://doi.org/10.20546/ijcmas.2018.709.276 